\title{
Numerical modelling of hydrodynamic pressures on dams
}

\author{
Loizos Pelecanos, Stavroula Kontoe, Lidija Zdravković \\ Department of Civil \& Environmental Engineering, Imperial College, London SW7 $2 A Z$
}

\begin{abstract}
This paper discusses several considerations related to appropriate numerical modelling of the reservoir hydrodynamic pressures on dams. The reservoir is modelled with 8-noded isoparametric displacement based solid finite elements. The study includes both stiff and flexible dams with vertical and sloped upstream faces under ramp, harmonic and random acceleration loads. The numerical results were compared and found to be in good agreement with available closed-form solutions. The same approach may be used in analyses of other waterfront structures such as quay walls.
\end{abstract}

Keywords: hydrodynamic pressures, dams, solid finite elements, reservoir, dynamic analysis

\section{Introduction}

The seismic behaviour of dams has long been studied [14] and several 3 methods of analysis were developed such as the pseudo-static [36] [32], the 4 shear beam [1] and the dynamic finite element [4,5] methods. Significant 5 progress was made regarding the dynamic characteristics of inhomogeneous visco-elastic dams $[10,11]$ and the seismic response of nonlinear elasto-plastic dams $[42,13]$. However, most of the analyses neglect the hydrodynamic pressures from the upstream reservoir and consider only the hydrostatic part of the reservoir pressures.

The hydrodynamic pressures on dams during earthquakes were first investigated by Westergaard [40] who considered a stiff dam with a vertical upstream face under harmonic loading. Zangar [43] [44] and Chwang [9] considered dams with a sloped upstream face whereas Liu [25] considered a 
sloped reservoir base. Moreover, the effects of the reservoir water compressibility were studied by Chopra [6] who showed that the magnitude of the total hydrodynamic force on the dam from a compressible reservoir depends on the frequency of the applied loading. In addition, the work of Chopra [6] was extended to investigate the hydrodynamic pressures due to random acceleration loading and a closed-form solution was developed.

A number of analytical solutions were developed [40] [44] [6] [3] [27] covering several aspects of the problem (such as slope angle, water compressibility, nature of load etc.) and provided various solutions for the magnitude and distribution of the hydrodynamic pressures on dams. However, they suffered from several assumptions and limitations (such as simple geometries, undeformable dams etc.). More elaborate problems involving complicated geometries, deformable and inhomogeneous dams required discretisation of the reservoir domain [16], so that reservoir-dam interaction can be fully analysed. To model the reservoir, various techniques have been developed, such as Eulerian [30] and Lagrangian [41] fluid finite elements, coupling of Finite Element and Boundary Element methodologies [38] [33] and development of advanced boundary conditions [34] [19] [15] [39] [31].

This paper investigates the numerical modelling of the hydrodynamic pressures by discretising the reservoir domain. The reservoir is modelled with two-dimensional plane-strain displacement-based isoparametric quadrilateral solid finite elements (FEs) which are the same as those used to model the dam structure. The investigation includes the upstream reservoir boundary condition (BC) and its distance from the dam, the dam-reservoir and foundation-reservoir interfaces, the material properties of the reservoir, the angle of the dam slope and various types of loading.

\section{Statement of the problem}

The problem under study is shown schematically in Figure 1. It consists of a dam (1) which retains a large volume of water in the reservoir (2) and rests on the ground (3) which serves as the foundation of the dam. Under seismic or general dynamic conditions, the reservoir induces hydrodynamic pressures on the upstream (US) dam face, A-B. The hydrodynamic pressures induced on the dam depend on the magnitude and the frequency characteristics of the load as well as the properties of the dam, the foundation and the reservoir.

In order to model efficiently and economically the hydrodynamic pressures, the US reservoir is truncated at some distance from the dam, (C-D). 
Likewise, the foundation soil is truncated at some distance from the dam and the reservoir (E-F-G-C). On both soil and reservoir boundaries, special absorbing boundary conditions (BCs) need to be applied so that reflection of outgoing waves is avoided.

Therefore, issues that need to be considered for appropriate modelling of the hydrodynamic pressures include: the type of the absorbing $\mathrm{BC}$ on the upstream reservoir boundary (C-D), the distance of this BC (B-C), the damreservoir and foundation-reservoir interfaces $(\mathrm{A}-\mathrm{B}-\mathrm{C})$ and the geometric and material properties of the reservoir (A-B-C-D).

\section{Ramp Acceleration}

This section concentrates on the evaluation of the hydrodynamic pressures on a stiff (undeformable) dam with a vertical upstream face under a ramp acceleration load. The modelling of hydrodynamic pressures on dams was recently investigated by Küçükarslan et al. [23] who represented the reservoir in their analyses with Eulerian fluid elements. Their study considered a stiff dam with a vertical upstream face of height $\mathrm{H}=180 \mathrm{~m}$, following the work of Tsai et al. [37], and examined the evolution of hydrodynamic pressures at the base of the dam (Point B in Figure 1) with time, under the ramp acceleration load shown in Figure 2.

\subsection{Upstream boundary condition}

Following the work of Küçükarslan et al. [23], analyses were carried out using the dam-reservoir system shown in Figure 3 under the above-mentioned ramp acceleration. The reservoir was modelled with 8-noded isoparametric displacement based solid elements (Figure 19). All the analyses carried out were two-dimensional plane-strain dynamic in the time-domain using the FE software ICFEP (Imperial College Finite Element Program) [29]. The time-integration scheme employed was the generalised $\alpha$-method of Chung \& Hulbert [8] which is able to use numerical damping to selectively filter high frequencies (spectral radius at infinity, $\rho_{\infty}=9 / 11$, see Kontoe et al. [21]) and the time step used was $\Delta \mathrm{t}=0.002 \mathrm{sec}$.

In Figure 3, A-B-F-E represents a stiff dam with a vertical upstream face (A-B), A-B-C-D represents the reservoir and F-C-H-G represents a stiff rock underneath the reservoir. The height of the reservoir was $\mathrm{H}=180 \mathrm{~m}$, whereas five values were adopted for the length of the reservoir, $\mathrm{L}=540,960,1260$, 1800 and $2400 \mathrm{~m}$ (i.e. $\mathrm{L} / \mathrm{H}=3,5.33,7,10$ and 13.33). The width of the stiff 


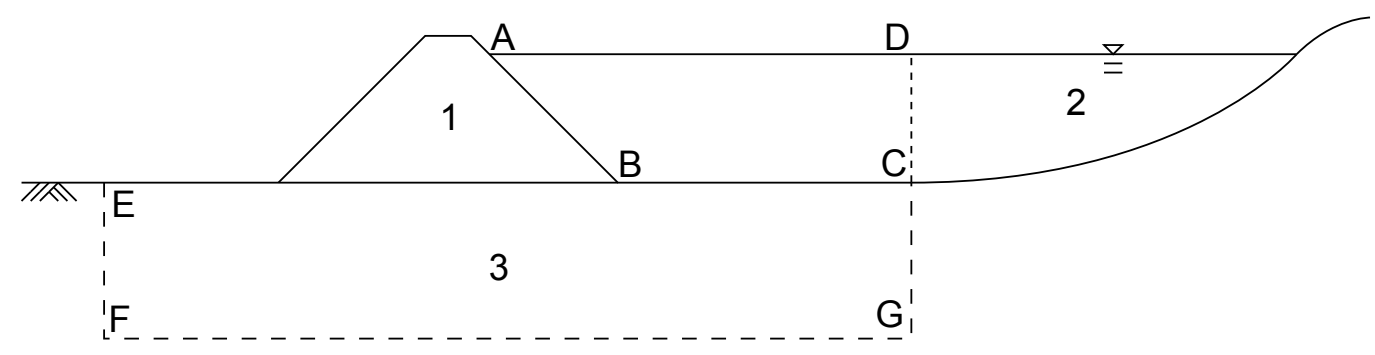

Figure 1: Geometry of the dam-reservoir-foundation system: (1) dam, (2) reservoir, (3) foundation soil, US dam face A-B, US reservoir boundary C-D and foundation boundary E-F-G-C.

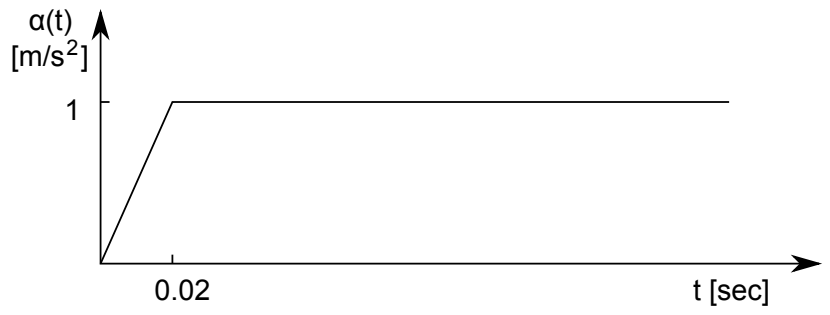

Figure 2: The ramp acceleration load used by Küçükarslan et al. [23]

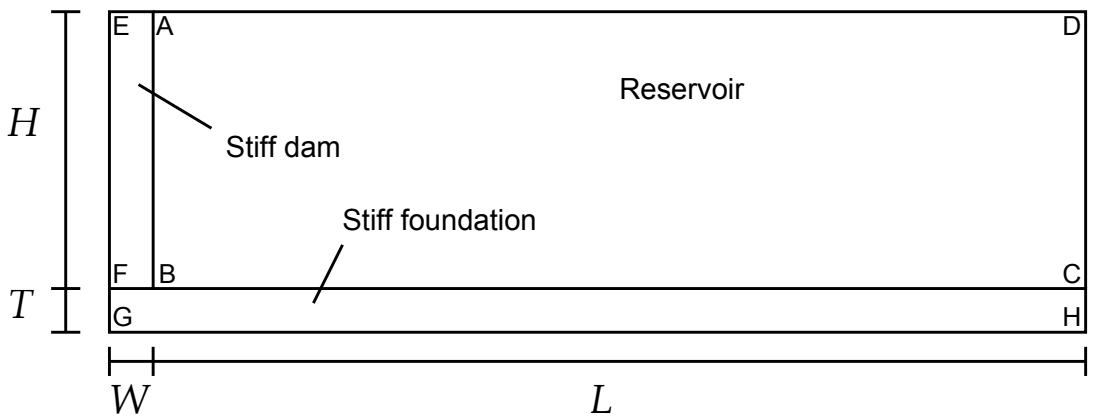

Figure 3: Geometry of the dam-reservoir system considered 
dam, $W$ and the thickness of the foundation, $T$ were $18 \mathrm{~m}$. The maximum element dimension, $d$ used was $4.5 \mathrm{~m}(=\mathrm{H} / 40)$. The load was applied as prescribed values of acceleration in the horizontal direction along the bottom and left vertical boundaries, while the displacements in the vertical direction were restricted to be equal to zero. Four boundary conditions (BCs) were considered for the upstream reservoir boundary (CD):

- Free, i.e. zero stress and displacement in the horizontal and vertical directions respectively

- Viscous [26], i.e. dashpots in the horizontal and zero displacements in the vertical direction

- Cone [20], i.e. dashpots and springs in the horizontal and zero displacements in the vertical direction

- Viscous with a constant hydrostatic pressure

As far as the last BC is concerned, it should be noted that, according to Parrinello \& Borino [28] (who followed the Lagrangian approach to discretise the reservoir domain), the Sommerfeld radiation condition [34] [35] may be represented by a series of dashpots and a hydrostatic stress at the boundary.

The reservoir water is modelled as a linear elastic material and its properties are the bulk modulus, $K_{w}=2.2 \cdot 10^{6} \mathrm{kPa}$ and the shear modulus, $G_{w}=100 \mathrm{kPa}$. A nominal value of the shear modulus was adopted to avoid numerical instability without causing unrealistic shear wave propagation in the water. The dam and foundation (A-B-C-H-G-F-E in Figure 3) were considered as rigid, therefore the bulk modulus assigned was $K_{d}=10^{8} \cdot K_{w}=2.2 \cdot 10^{14} \mathrm{kPa}$. No material (viscous Rayleigh) damping was specified in the reservoir, dam or foundation domains. The dashpots and the springs are defined by Equations 1 and 2 respectively.

$$
\begin{gathered}
\sigma=\rho V_{p} \dot{u} \\
\sigma=\rho \frac{V_{p}^{2}}{2 r} u
\end{gathered}
$$

where $\sigma$ is a normal stress on the boundary, $\rho$ is the density of the material the $\mathrm{BC}$ has been applied to (i.e. water in this case), $V_{p}$ is the p-wave velocity of the water $(=1483 \mathrm{~m} / \mathrm{s}), r$ is the distance of the boundary from 


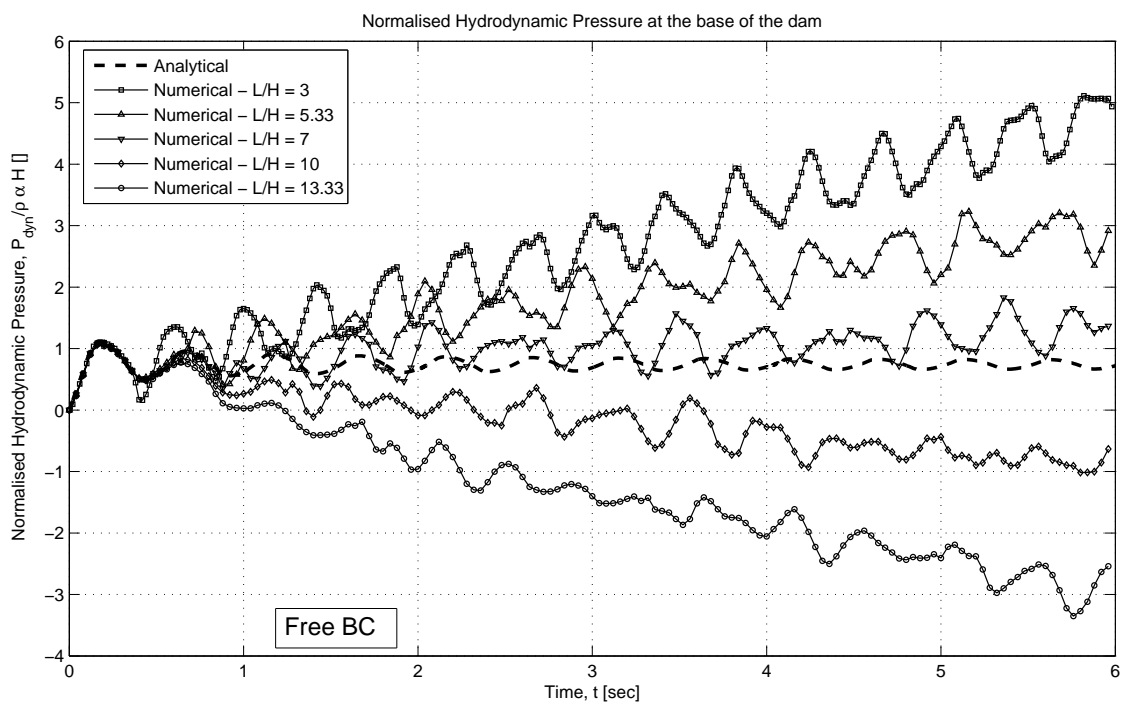

Figure 4: Hydrodynamic pressures at the base of the dam due to the ramp acceleration for the Free BC

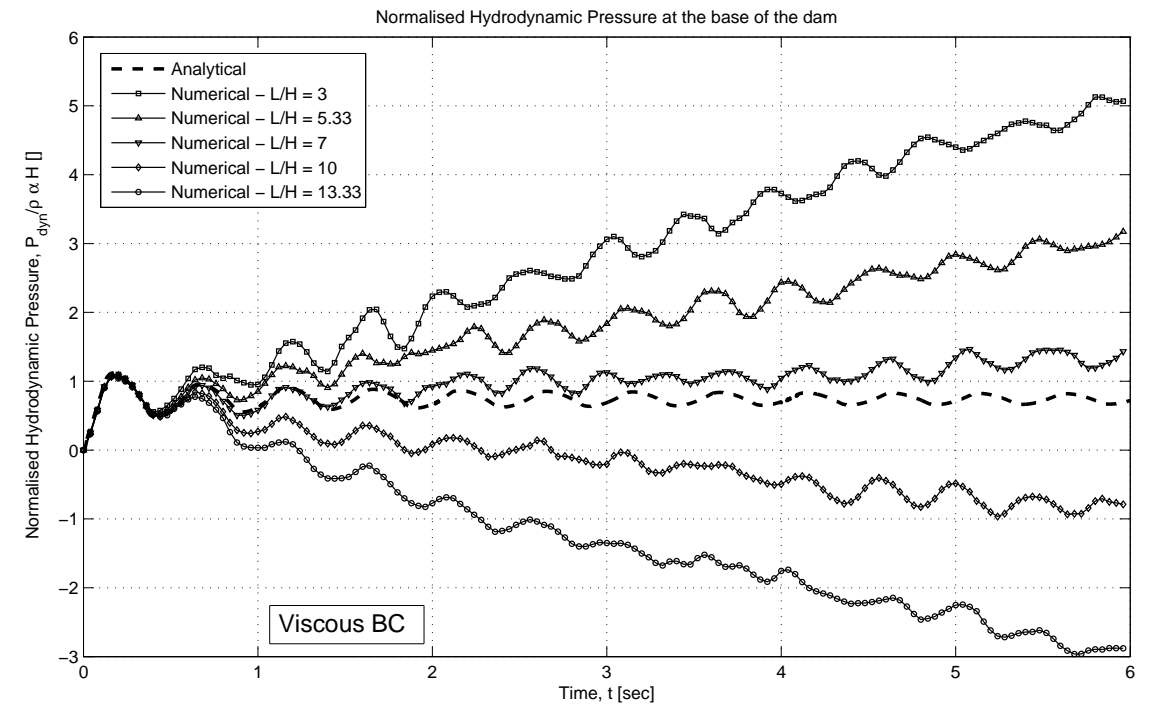

Figure 5: Hydrodynamic pressures at the base of the dam due to the ramp acceleration for the Viscous BC 


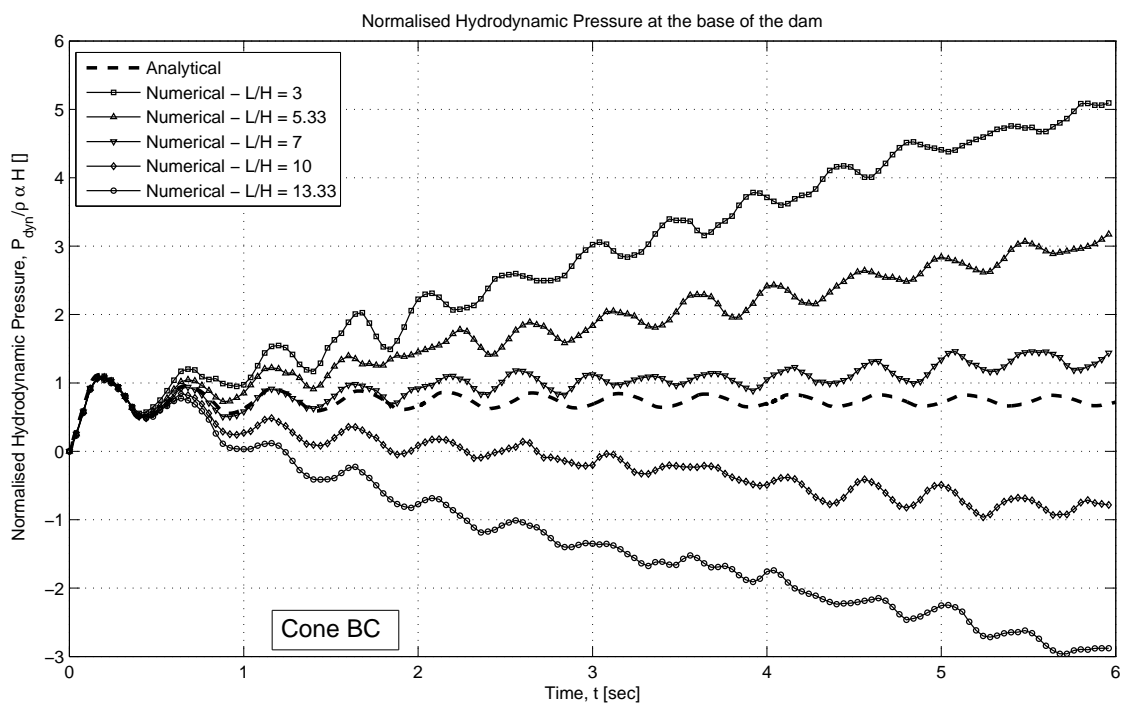

Figure 6: Hydrodynamic pressures at the base of the dam due to the ramp acceleration for the Cone BC

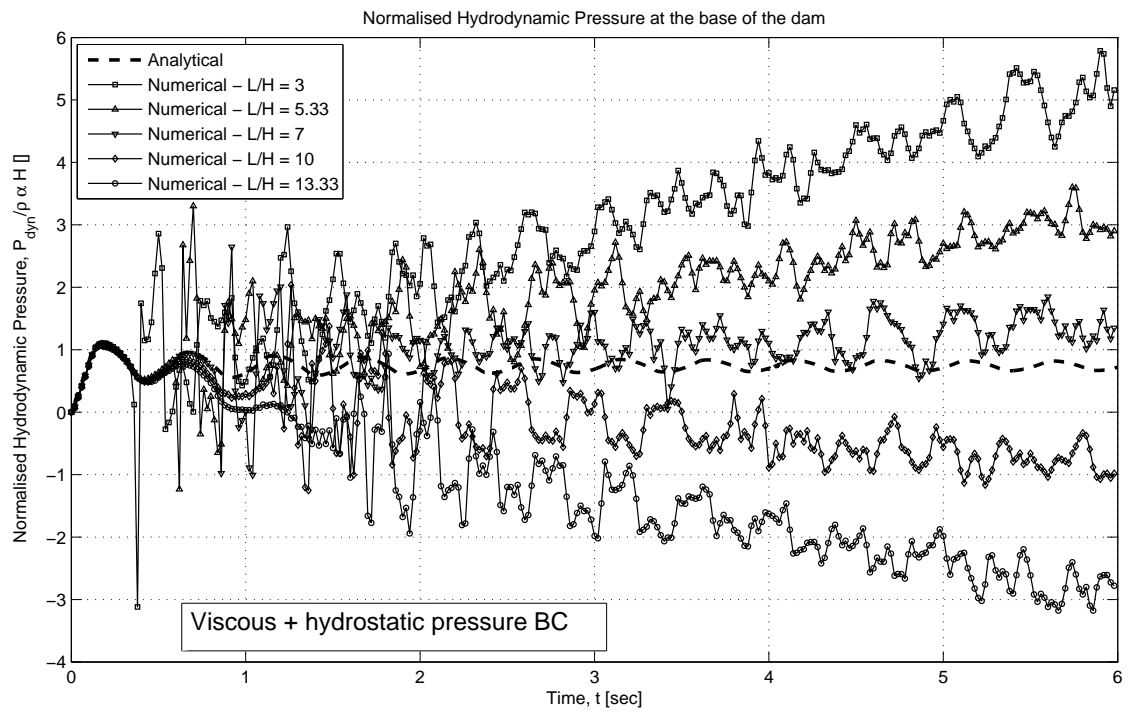

Figure 7: Hydrodynamic pressures at the base of the dam due to the ramp acceleration for the Viscous + hydrostatic stress BC 
the excitation source (taken as equal to the length, $\mathrm{L}$ of the reservoir), $u$ and $\dot{u}$ are the displacement and velocity in the horizontal direction respectively. More details about these BCs may be found in Kontoe et al. [22].

Figures $4-7$ show the hydrodynamic pressure at the base of the dam (Point B) with time for the four different BCs considered. The hydrodynamic pressures, $P_{d y n}$, are normalised with respect to $\rho a H$, where $\rho$ is the mass density of water, $a=1 \mathrm{~m} / \mathrm{s}^{2}$ is the maximum value of the ramp acceleration load (see Figure 2) and $H$ is the height of the reservoir. The numerical results are compared to the analytical solution which was calculated using the relation of Chopra [6], given by Equation 3 .

$$
p(y, t)=\frac{4 \gamma_{w} V_{p}}{\pi g} \sum_{n=1}^{+\infty} \frac{(-1)^{n-1}}{2 n-1} \cos \left(\lambda_{n} y\right) \int_{0}^{t} \ddot{u}_{g}(\tau) J_{o}\left[\lambda_{n} V_{p}(t-\tau)\right] d \tau
$$

where, $y$ is the vertical distance from the base of the dam, $t$ is the time, $\gamma_{w}$ is the unit weight of water, $V_{p}$ is the p-wave velocity of water, $\lambda_{n}$ is the $n^{t h}$ wavelength, $\ddot{u}_{g}(t)$ is the ground acceleration and $J_{o}(\cdot)$ is a Bessel Function of the first kind of order 0. Equation 3 refers to the hydrodynamic pressures on a rigid dam with a vertical upstream face from a rectangular reservoir under general horizontal ground acceleration.

As it may be observed from Figures 4 - 7, none of the four BCs satisfactorily captured the analytical solution for the hydrodynamic pressures, regardless of the $\mathrm{L} / \mathrm{H}$ ratio. In all four cases the first half cycle is predicted correctly, whereas the hydrodynamic pressures are generally increasing or decreasing with time for shorter and longer meshes respectively. Moreover, the amplitude of the pressure fluctuations for the Free BC is significantly larger than that of the pressures from the analytical solution. The amplitude of the fluctuations for both the Viscous and the Cone BCs is more comparable to the analytical solution. The results for the Viscous + hydrostatic pressure $\mathrm{BC}$ show some spurious peak values of the pressure which occur at different times according to the length of the mesh. The longer the FE mesh, the later the peaks appear. This is believed to be due to the specification of a constant stress at the boundary which causes reflection of the waves back towards the dam.

\subsection{Reservoir-dam and reservoir-foundation interface}

The analyses were repeated after the introduction of zero-thickness isoparametric interface elements [12] [29] at the reservoir-dam and reservoir-foundation 
interfaces (ABC in Figure 3). The reason for introducing these elements is to allow relative movement between the reservoir and the solid material. For this reason, a very high normal $\left(k_{N}=10^{8} \mathrm{kN} / \mathrm{m}\right)$ and very low shear stiffness $\left(k_{S}=1 \mathrm{kN} / \mathrm{m}\right)$ were assigned to these elements so that only shear relative movement occurs.

Figures 8 - 11 show the evolution of the hydrodynamic pressures at the base of the dam (Point B) with time for the all four BCs. As it may be observed, the results are now in better agreement with the analytical solution as the general increase or decrease of the pressures with time disappeared. However, the amplitude of the fluctuations for the Free BC (Figure 8) is still larger than that of the analytical solution and the pressures for the Viscous + hydrostatic pressure BC (Figure 11) still show some spurious peaks. As far as the Viscous (Figure 9) and the Cone (Figure 10) BCs are concerned, a good agreement is obtained although there are still some differences and these are mainly a slight increase of the amplitude and a small shortening of the period of the pressure fluctuations, which seem to be more severe for the shorter FE meshes.

Moreover, Figures 12 and 13 show the comparison between the analytical and the numerical (with the Viscous BC) hydrodynamic pressure timehistories at the base of the dam for $L / H=3$ and 13.33 respectively. It is shown that for the shorter mesh, the increase in the amplitude of the pressure fluctuations occurs much earlier than that for the longer mesh and also the shortening of the period is more pronounced. Figure 14 compares the computed hydrodynamic pressures for $L / H=7$ with both the analytical solution and the numerical solution of Küçükarslan et al. [23] (obtained by adopting the Eulerian approach). It is shown that the agreement of both numerical approaches (Eulerian fluid FEs and elastic solid FEs) with the analytical approach of Chopra is acceptable. Finally, Figure 15 compares the distribution of the peak hydrodynamic pressure on the upstream face of the dam for all 5 lengths computed with the Viscous BC with the analytical solution, showing an excellent agreement (as it occurs during the first half cycle). It should be noted that the results for the case of the Cone BC with interface elements are almost identical to the results of the Viscous BC and are not shown here for brevity.

Of course, the ramp acceleration may not be the most suitable load to determine an appropriate length of the reservoir and consequently the distance of the boundary from the problem of interest. However, so far it may be concluded that the Viscous and the Cone BCs perform well as absorbing 


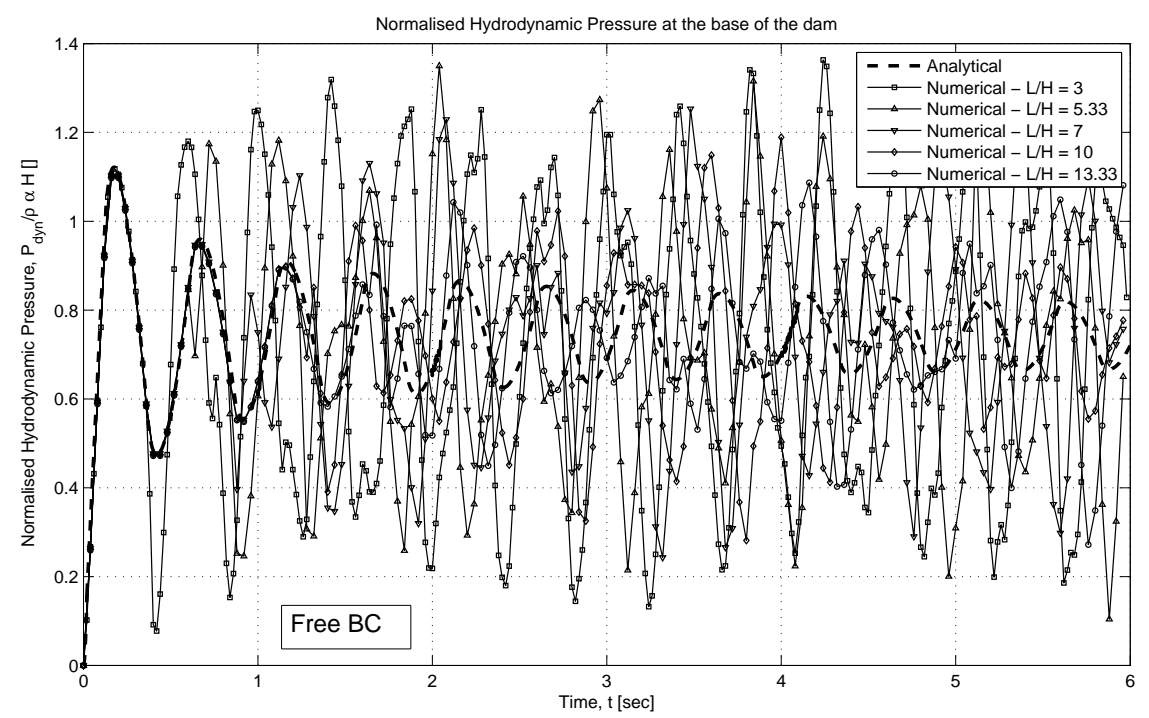

Figure 8: Hydrodynamic pressures at the base of the dam due to the ramp acceleration for the Free BC with interface elements

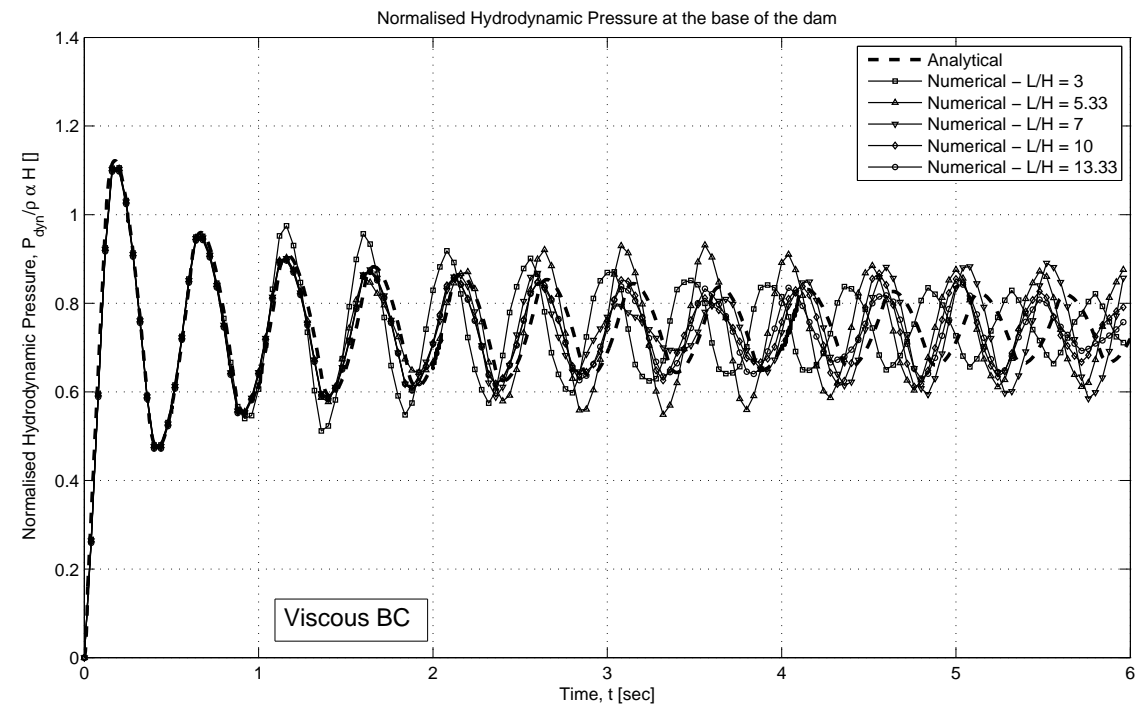

Figure 9: Hydrodynamic pressures at the base of the dam due to the ramp acceleration for the Viscous BC with interface elements 


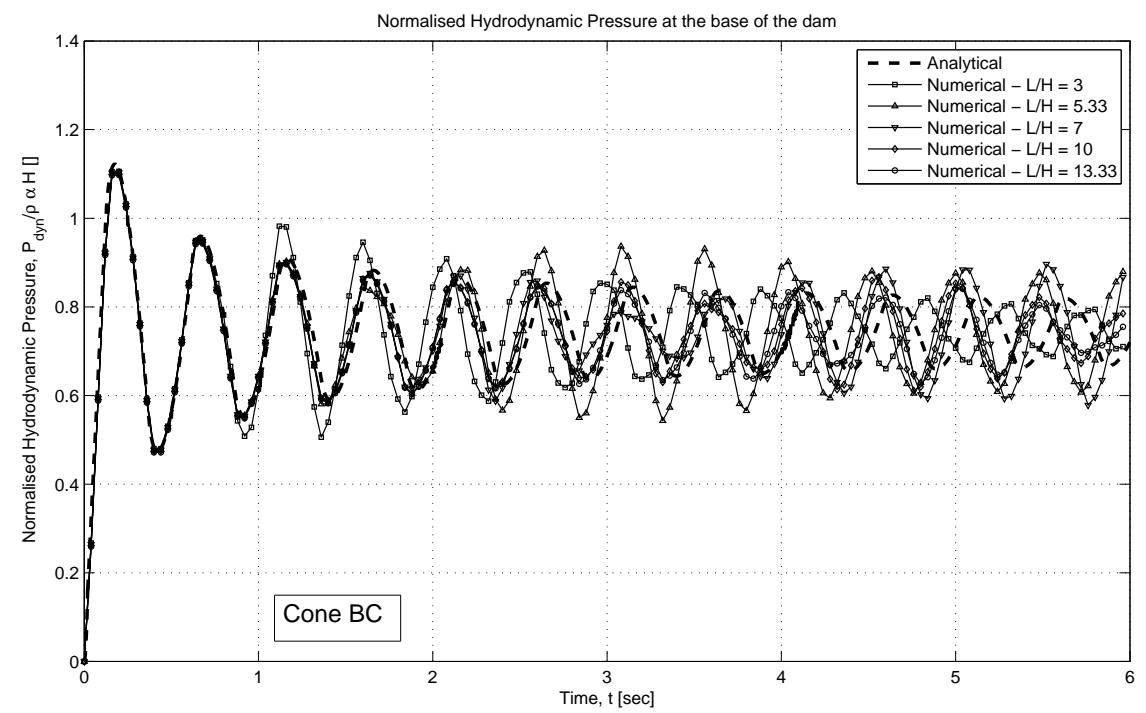

Figure 10: Hydrodynamic pressures at the base of the dam due to the ramp acceleration for the Cone $\mathrm{BC}$ with interface elements

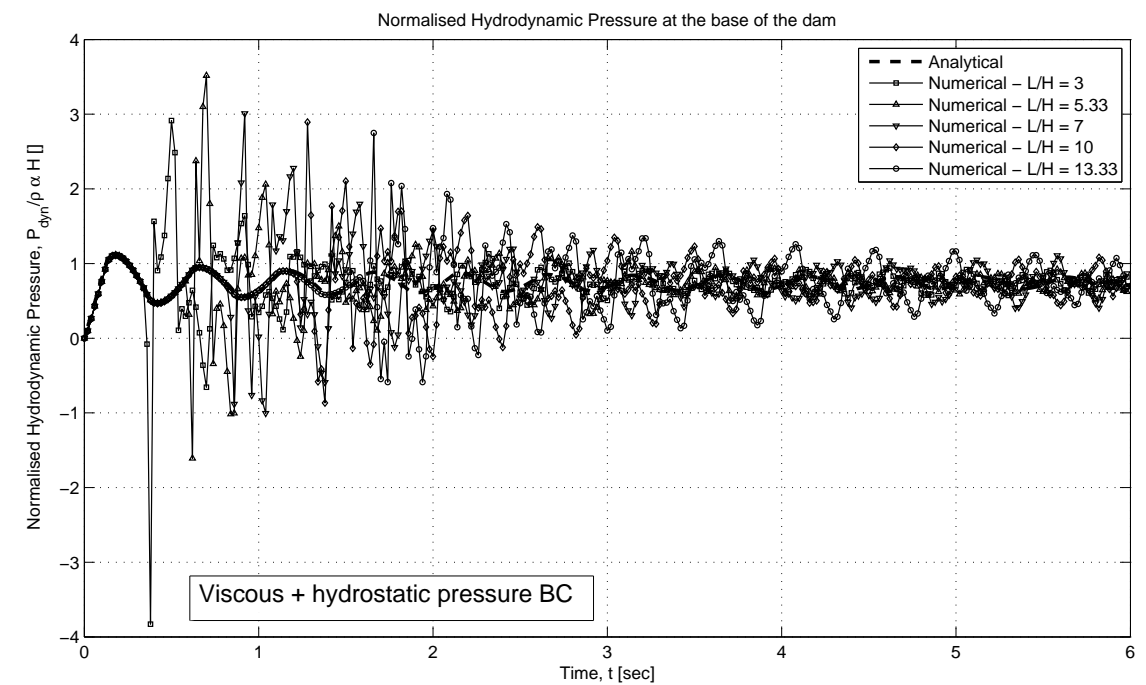

Figure 11: Hydrodynamic pressures at the base of the dam due to the ramp acceleration for the Viscous + hydrostatic stress BC with interface elements 


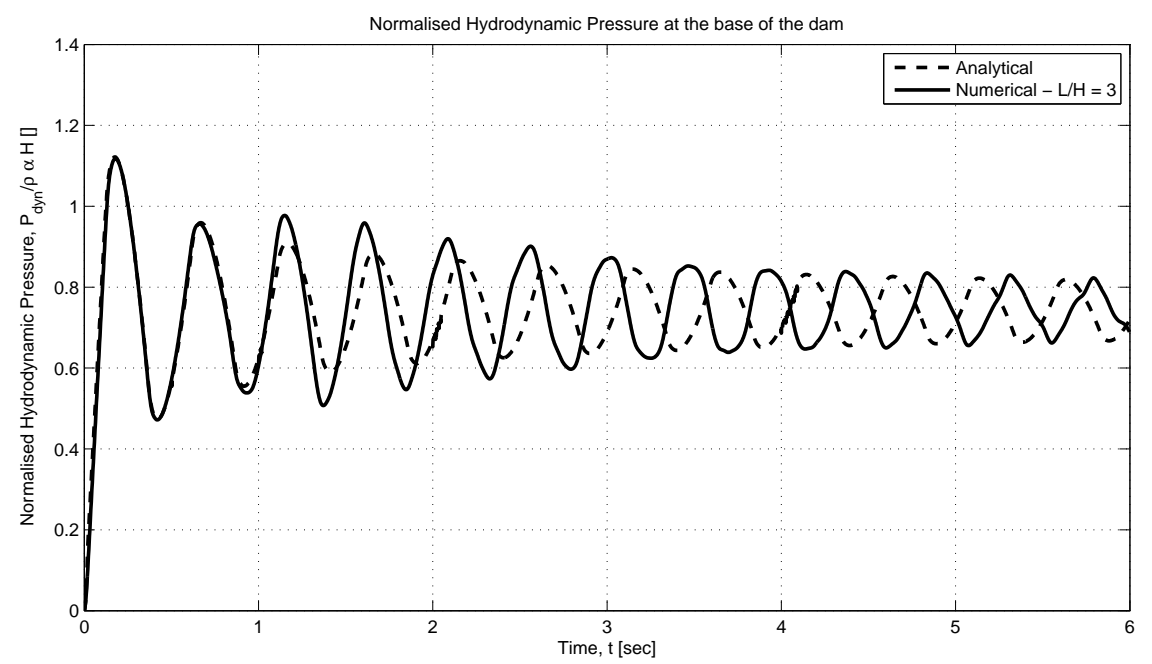

Figure 12: Hydrodynamic pressures at the base of the dam due to the ramp acceleration with the Viscous $\mathrm{BC}$ for $L / H=3$

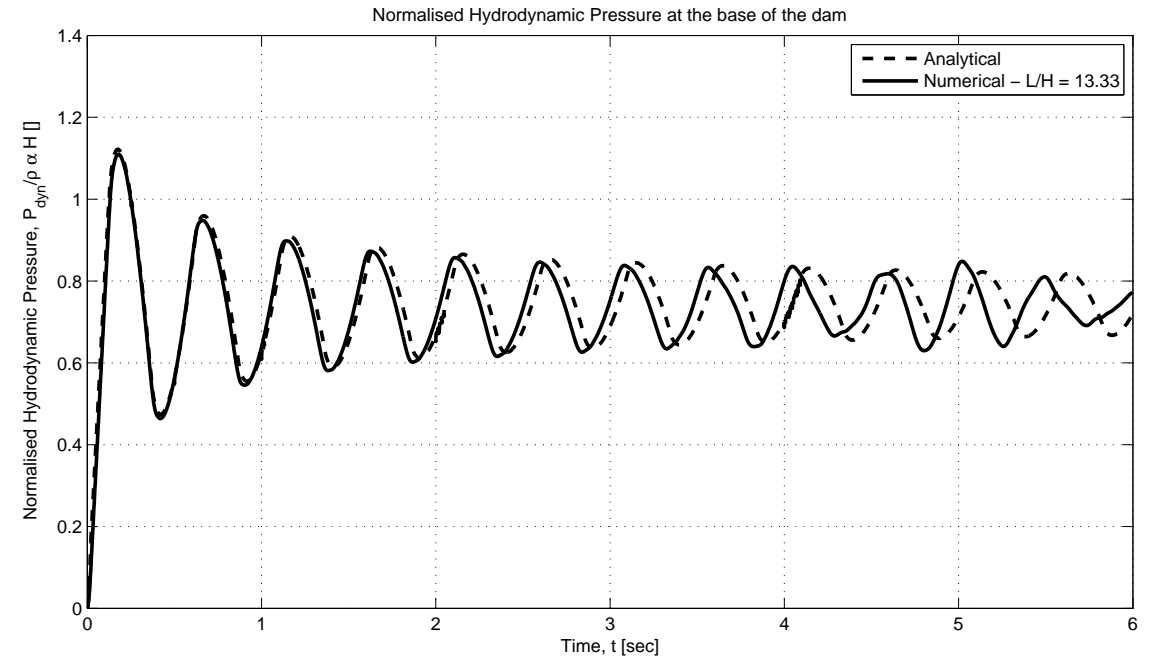

Figure 13: Hydrodynamic pressures at the base of the dam due to the ramp acceleration with the Viscous $\mathrm{BC}$ for $L / H=13.33$ 


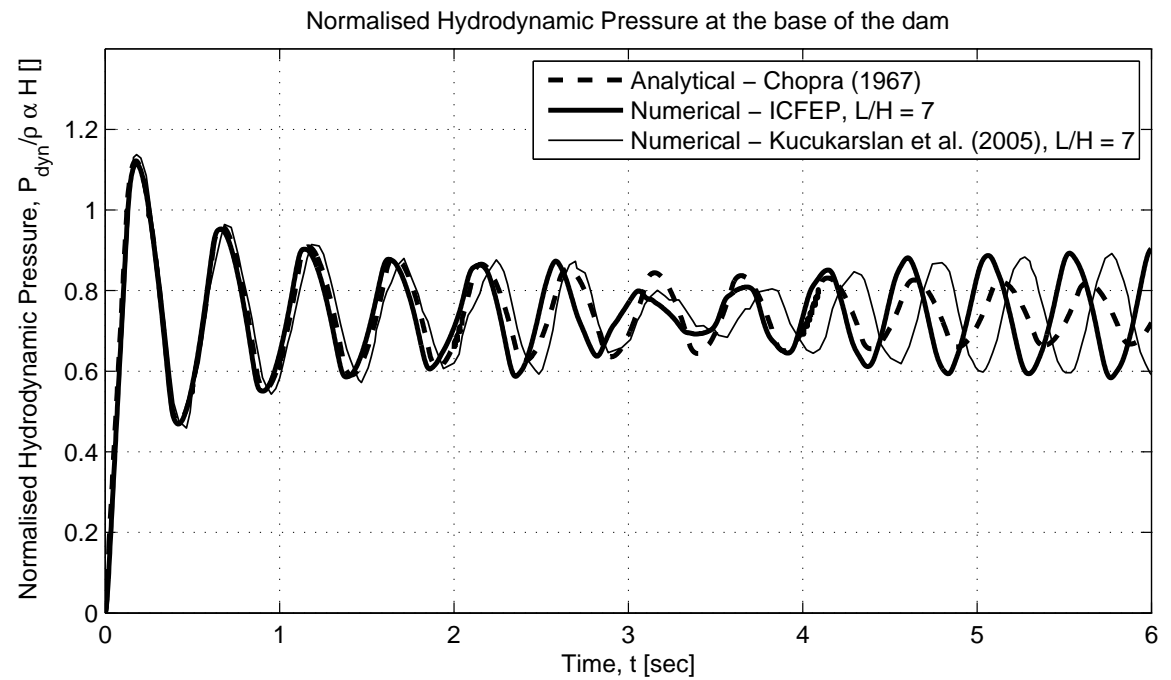

Figure 14: Comparison of the hydrodynamic pressures at the base of the dam due to the ramp acceleration with the Viscous $\mathrm{BC}$ for $L / H=7$ against the analytical solution of Chopra [6] and the numerical results of Küçükarslan et al. [23].

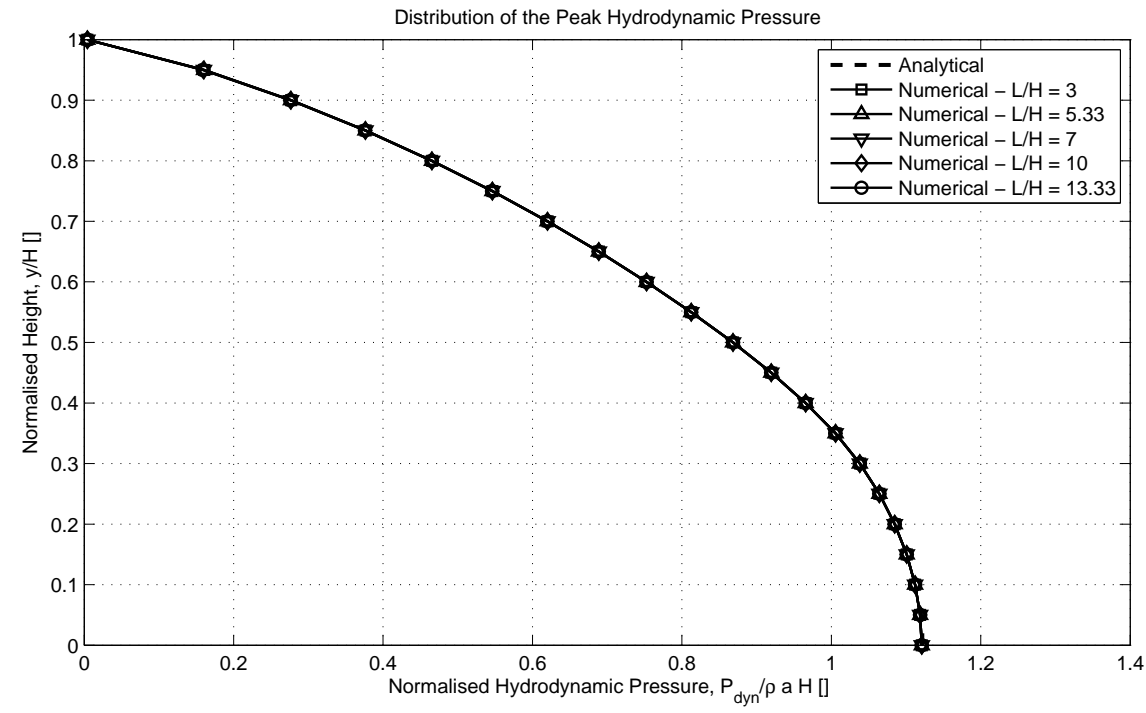

Figure 15: Distribution of the peak hydrodynamic pressure on the face of the dam due to the ramp acceleration for the Viscous BC 
BCs on the reservoir and that interface elements with appropriate stiffness should be placed at the interface between the reservoir and the solid domains (dam and foundation). It is therefore concluded that both the "Free" and "Viscous + hydrostatic pressure" BCs are not appropriate absorbing BCs and will not be considered further in this study.

\section{Harmonic Acceleration}

\subsection{Frequency Response}

As mentioned earlier, Chopra [6] investigated the hydrodynamic pressures on dams under harmonic loading and expressed the results in terms of a spectrum of forces. In order to examine the performance of the Viscous and Cone BCs under a wide range of loading frequencies, the same analyses were repeated for different loading frequencies according to Equation 4, with amplitude $a_{0}=1 \mathrm{~m} / \mathrm{s}^{2}$ for 40 cycles.

$$
a(t)=a_{0} \cos \omega t
$$

where, $a(t)$ is acceleration, $a_{0}$ is the amplitude of the harmonic acceleration, $\omega$ is the circular frequency of the load and $t$ is time. The time step used was $\Delta \mathrm{t}=\mathrm{T} / 40$, where $\mathrm{T}=2 \pi / \omega$.

Figures 16 and 17 show the ratio of the total hydrodynamic force, $F_{d y n}$ (hydrodynamic pressures integrated over the upstream dam face at steady state conditions, i.e. when the hydrodynamic pressures take the form of a periodic function), over the hydrostatic force, $F_{s t}$, multiplied by the acceleration of gravity, $g$, against the frequency ratio, $\Omega=\omega / \omega_{1}$. The parameter $\omega$ refers to the circular frequency of the load and $\omega_{1}$ to the fundamental circular frequency of the reservoir, given by Equation 5 [6].

$$
\omega_{1}=\frac{\pi V_{p}}{2 H}
$$

where $H$ is the height of the reservoir and $V_{p}$ is the p-wave velocity of water. The values of the ratio $g \cdot F_{d y n} / F_{s t}$ at the natural frequencies of the reservoir $\left(\omega / \omega_{1}=1,3,5, \ldots\right)$ are not included as the hydrodynamic pressures, $F_{d y n}$, from the reservoir become infinite due to resonance.

As it may be observed, a generally good agreement is obtained for the whole spectrum of frequencies for both BCs and in fact their performance is almost identical. This suggests that both of these BCs can be applied on 


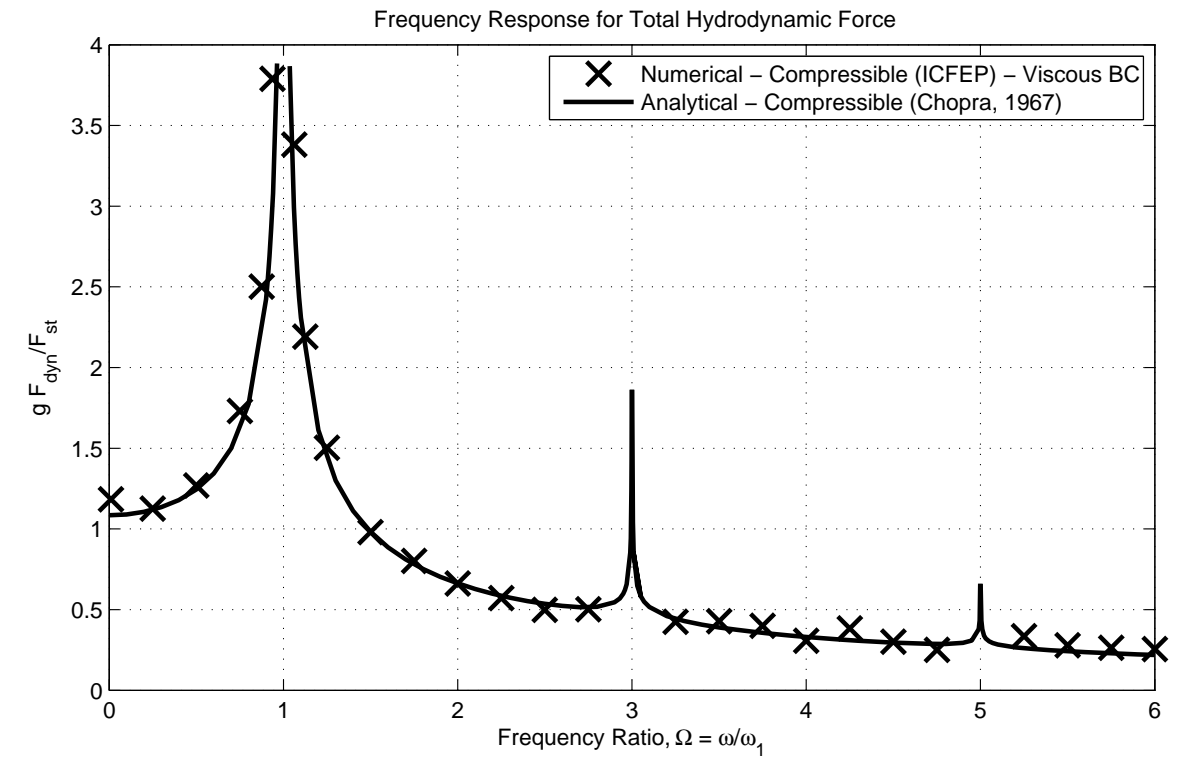

Figure 16: Frequency response of the total hydrodynamic induced by a compressible reservoir due to horizontal harmonic loading with the Viscous BC

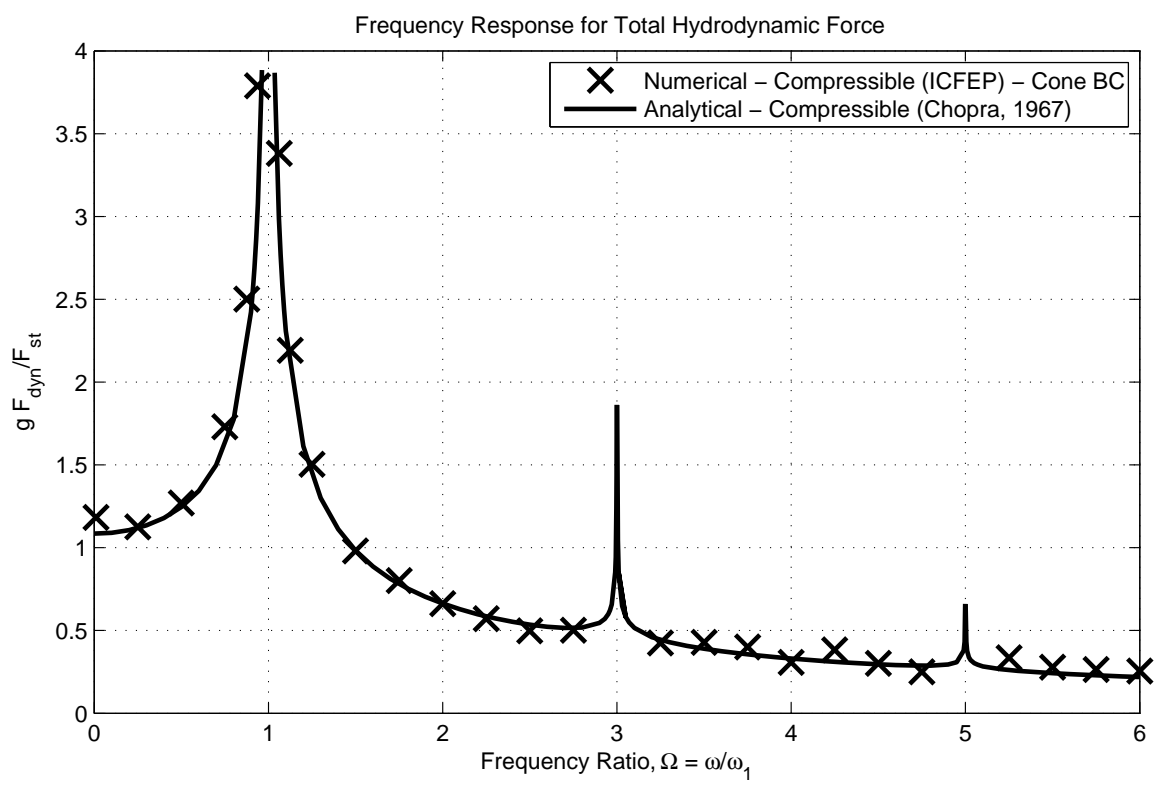

Figure 17: Frequency response of the total hydrodynamic induced by a compressible reservoir due to horizontal harmonic loading with the Cone BC 
the upstream boundary of the reservoir in order to model the hydrodynamic pressures on dams due to a dynamic load of a wide range of frequencies.

\subsection{Water compressibility}

The significance of considering the true compressibility of water was highlighted by Chopra [6]. In order to examine the behaviour of the numerical model if water is considered incompressible, the analyses of the previous section with the Viscous BC were repeated for the same loading frequencies. The compressibility of the water, $K_{w}$ was taken as 100000 times the real value (i.e. $K_{w}=2.2 \cdot 10^{11} \mathrm{kPa}$ ). The resulting force spectrum is shown in Figure 18.

The numerical results for incompressible water agree with the analytical result of Westergaard [40] (Equation 6), which was also confirmed by Chopra $[6]$.

$$
\frac{g \cdot F_{d y n}}{F_{s t}}=\frac{g \cdot 0.543\left(a_{0} / g\right) \gamma_{w} H^{2}}{1 / 2 \gamma_{w} H^{2}}=1.09
$$

The higher hydrodynamic pressures due to resonance for loading frequencies close to the natural frequency of the reservoir cannot be predicted, whereas the pressures for higher frequency loads are overestimated. It is therefore suggested that water compressibility should be taken into account by using the real value of bulk modulus of the water, $K_{w}$ in order not to underestimate or overestimate the pressures for different loading frequencies.

\subsection{Effect of element size}

A further investigation was carried out in order to examine the effect of the size of the reservoir elements on the hydrodynamic pressures. When modelling dynamic problems, care needs to be taken in order to appropriately model wave propagation and therefore a sufficient number of nodes should be provided to model the length of the propagating wave [26] [24] [2]. A very fine mesh could in one hand provide sufficient nodes; on the other hand, it would increase the computational cost. The aim is therefore to identify the largest element size that provides accurate results.

For this investigation, a FE mesh of height, $\mathrm{H}=90 \mathrm{~m}$ and length, $\mathrm{L}=900 \mathrm{~m}$ was employed. Eight-noded isoparametric quadrilateral elements [29] were used as shown in Figure 19. The Viscous BC was applied on the upstream reservoir boundary. The harmonic load is described by Equation 4 with a single value of $\omega$ so that the ratio $\omega / \omega_{1}=4$. The various element sizes used 


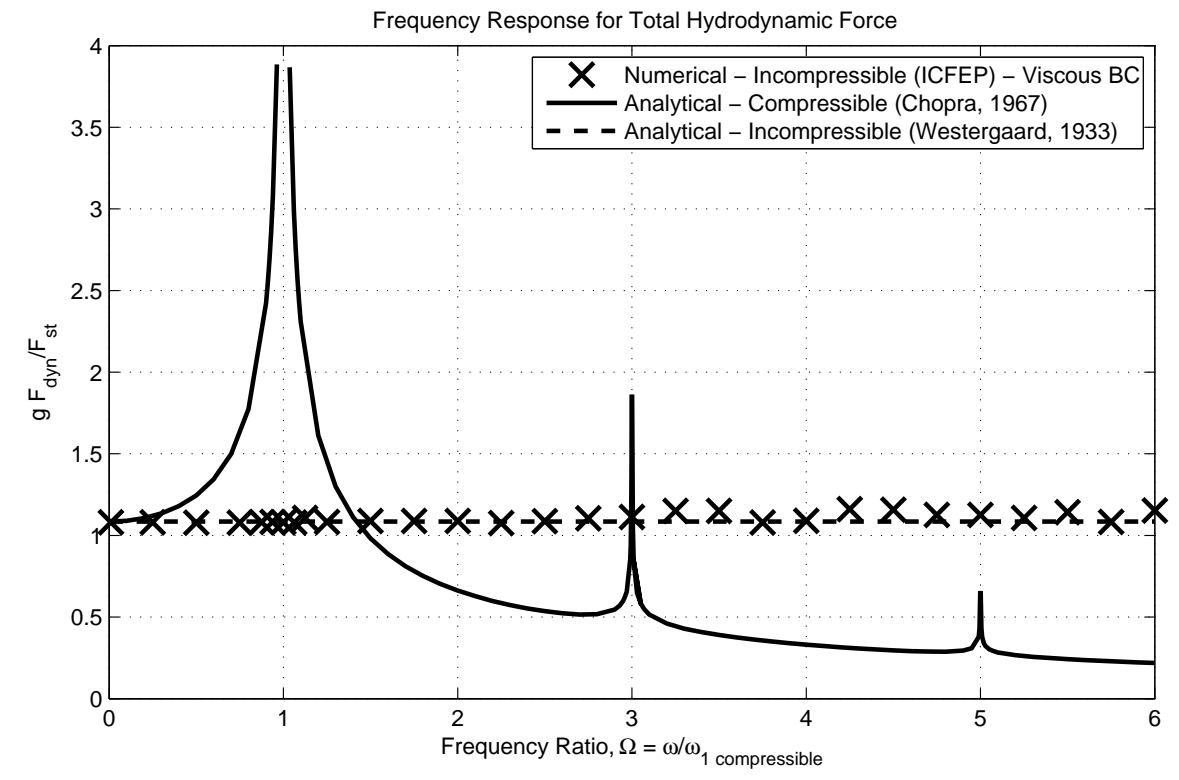

Figure 18: Frequency response of the total hydrodynamic induced by an incompressible reservoir due to horizontal harmonic loading

Table 1: Size of the reservoir finite elements considered

\begin{tabular}{|c|c|c|}
\hline CASE & Element size, d $[\mathbf{m}]$ & $H / d=\lambda / d$ \\
\hline 1 & 90 & 1 \\
2 & 45 & 2 \\
3 & 30 & 3 \\
4 & 22.5 & 4 \\
5 & 18 & 5 \\
6 & 15 & 6 \\
7 & 11.25 & 8 \\
8 & 9 & 10 \\
9 & 7.5 & 12 \\
10 & 6 & 15 \\
11 & 4.5 & 20 \\
\hline
\end{tabular}




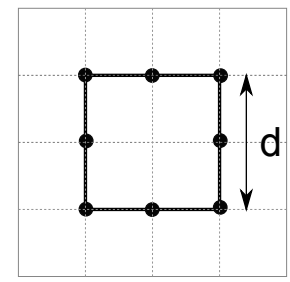

Figure 19: Eight-noded isoparametric quadrilateral element [29]

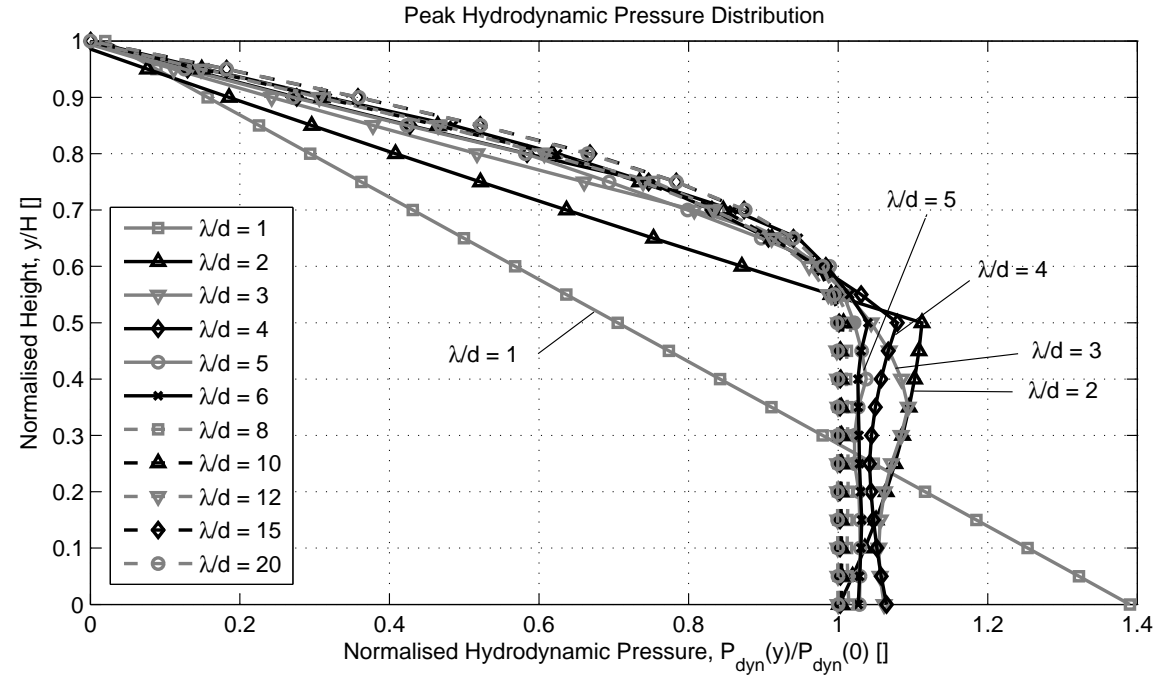

Figure 20: Distribution of the peak hydrodynamic pressure on the dam face for different element sizes 
are listed in Table 1 and are expressed as a fraction of the wavelength, $\lambda$. For a monochromatic load (i.e. single frequency, $f=\omega / 2 \pi$ ), the wavelength of a p-wave (with velocity, $V_{p}$ ) is given by Equation 7 .

$$
\lambda=\frac{V_{p}}{f}
$$

Considering the fundamental frequency of vibration of a reservoir, $f_{1}=$ $\omega_{1} / 2 \pi$ ( $\omega_{1}$ from Equation 5$)$, then the wavelength is given by Equation 8 .

$$
\lambda=\frac{4 H}{f / f_{1}}=\frac{4 H}{\omega / \omega_{1}}
$$

Figure 20 shows the distribution of the peak hydrodynamic pressure on the upstream face of the dam for all 11 values of the element dimension, $d$. The results from the finest mesh $(\lambda / d=20)$ are considered to be the most accurate because a large number of nodes has been provided to model the wavelength. As it may be observed from that figure, the peak hydrodynamic pressure obtained using elements of size equal or smaller than a fifth of the wavelength deviate significantly from the most accurate prediction, whereas the results for an element dimension equal to a sixth and an eighth of the wavelength are close. It is therefore suggested that if the reservoir is modelled with eight-noded quadrilateral solid elements, the side of these elements should be smaller than a fifth of the wavelength. This is in agreement with earlier work [2] which suggests that the size of 8-noded quadrilateral elements should be between a fifth and a quarter of the wavelength.

\section{Random Acceleration}

The final part of the investigation considered the behaviour of the reservoir under random acceleration, i.e. under seismic loading. The acceleration record of the 15/11/1975 Mexico earthquake recorded at the rock canyon of La Villita dam (maximum value, $a_{m}=\mathrm{PGA}=0.04 \mathrm{~g}$ ) was used as the input motion and it is shown in Figure 21. This section examines the distance of the upstream reservoir BC from the dam for both stiff and flexible dams with vertical and sloped upstream faces. Also, the value of the reservoir water shear modulus, $G_{w}$ is investigated. 


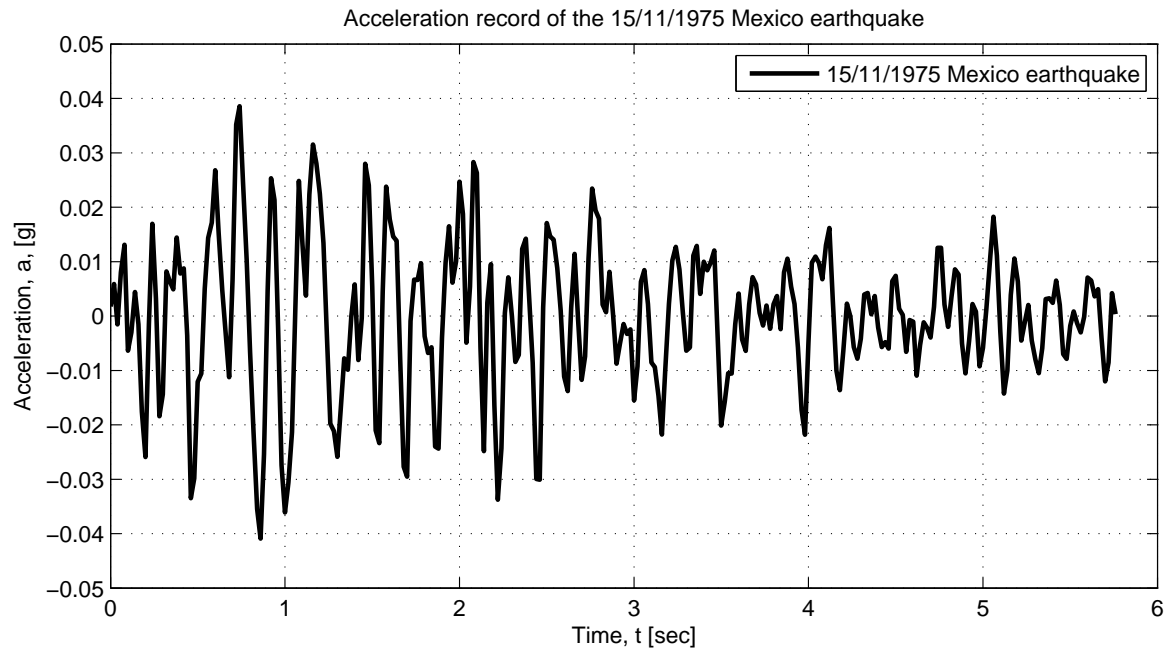

Figure 21: Accelerations recorded at the rock canyon of La Villita dam in Mexico during the 15/11/1975 Mexico earthquake

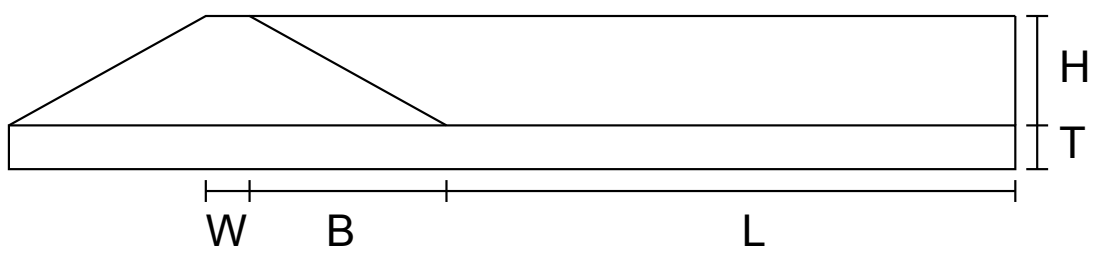

Figure 22: Geometry of the dam-reservoir system considered for the random acceleration load

Table 2: Values of the length of the mesh considered

\begin{tabular}{|c|c|}
\hline MESH & Length, L/H \\
\hline 1 & 0.5 \\
2 & 1 \\
3 & 2 \\
4 & 3 \\
5 & 4 \\
6 & 5 \\
7 & 8 \\
8 & 10 \\
9 & 12 \\
10 & 15 \\
\hline
\end{tabular}




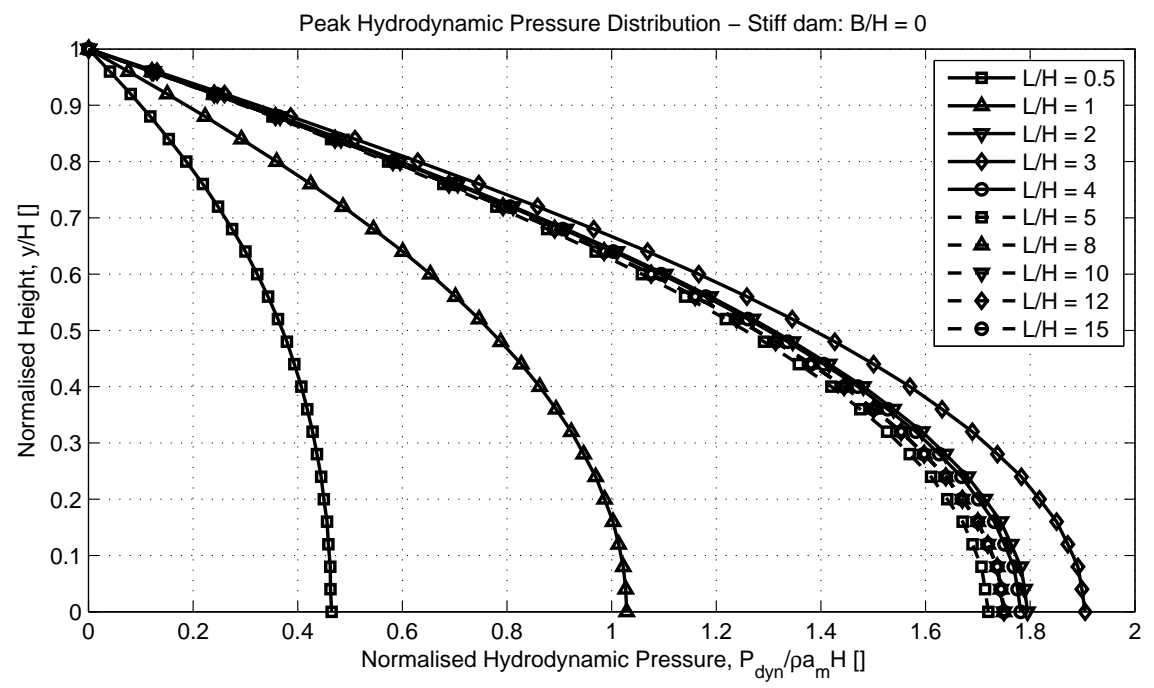

Figure 23: Distribution of the peak hydrodynamic pressure on the face of the dam due to the earthquake load - Stiff dam with vertical face $(\mathrm{B} / \mathrm{H}=0)$

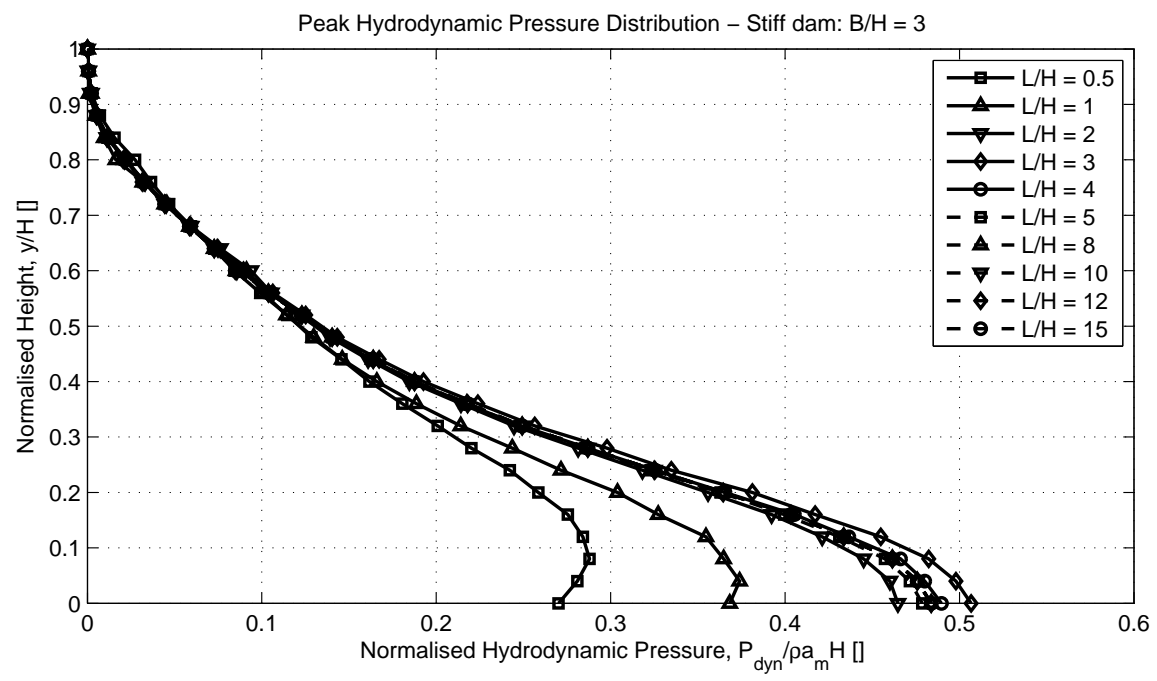

Figure 24: Distribution of the peak hydrodynamic pressure on the face of the dam due to the earthquake load - Stiff dam with sloped face $(\mathrm{B} / \mathrm{H}=3)$ 


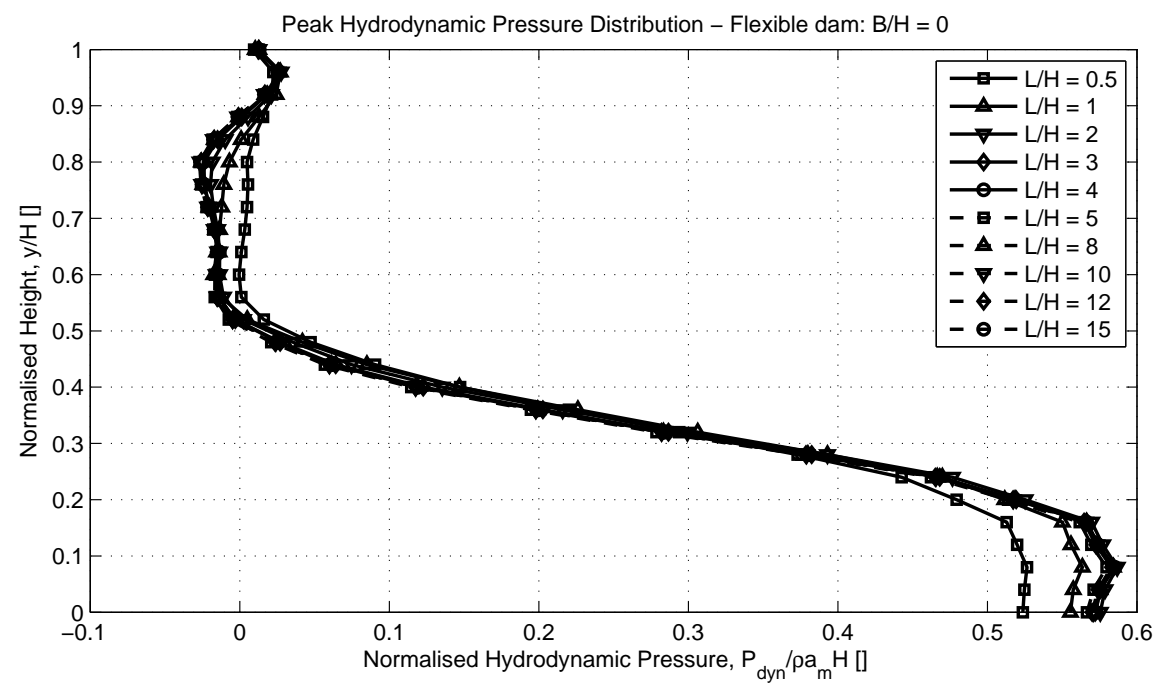

Figure 25: Distribution of the peak hydrodynamic pressure on the face of the dam due to the earthquake load - Flexible dam with vertical face

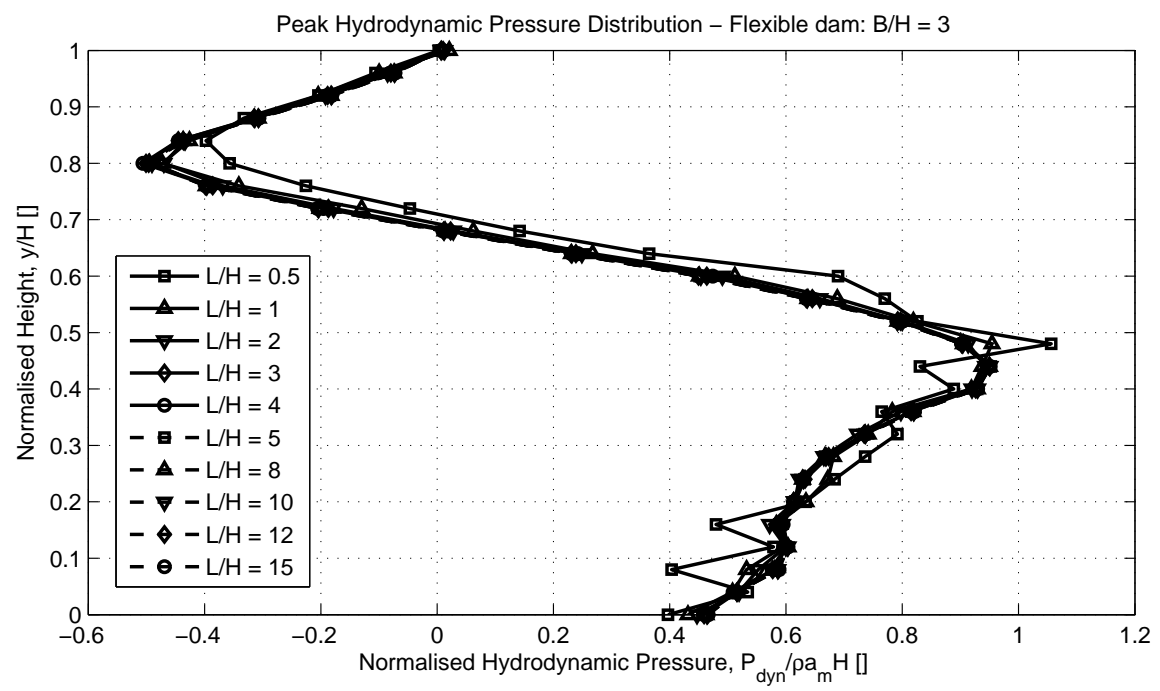

Figure 26: Distribution of the peak hydrodynamic pressure on the face of the dam due to the earthquake load - Flexible dam with sloped face 


\subsection{Sloped dam}

The investigations so far have been restricted to stiff (undeformable) dams with a vertical upstream face. However, earth dams are flexible compared to concrete gravity dams and have a sloped upstream face. This section investigates the effect of the slope and the flexibility of the dam on the distance of the upstream reservoir boundary, i.e. the length of the reservoir domain of the FE mesh. Analyses were performed with the acceleration record shown in Figure 21 for a vertical $(\mathrm{B} / \mathrm{H}=0)$ and a sloped dam $(3: 1$ horizontal:vertical, i.e. $\mathrm{B} / \mathrm{H}=3$ ) for various values of the length of the reservoir, L, as listed in Table 2 and shown in Figure 22. As it may be observed from Figure 22, $\mathrm{B}$ is the breadth of the dam face and $\mathrm{H}$ is the height of the reservoir. For all the analyses, the height of the reservoir, $\mathrm{H}$ was equal to $60 \mathrm{~m}$ and both stiff (undeformable) and flexible dams were considered. For the analyses assuming a flexible dam, material properties have been assigned to the dam that correspond to a shear wave velocity $V_{s}=300 \mathrm{~m} / \mathrm{s}$, which is considered a typical value for earth materials. The time step used was $\Delta \mathrm{t}=$ $0.02 \mathrm{sec}$.

Figures 23 - 26 show the distribution of the peak hydrodynamic pressure on the upstream face of the dam for a (i) stiff and vertical, (ii) stiff and sloped, (iii) flexible and vertical and (iv) flexible and sloped dam respectively. The hydrodynamic pressures are normalised with respect to $\rho a_{m} H$, where $\rho$ is the mass density of water, $a_{m}=0.04 \mathrm{~g}$ is the maximum value of the input acceleration load (see Figure 21) and $H$ is the height of the reservoir. The analyses for the longest mesh, i.e. $L / H=15$ are considered as the most accurate because the longer the distance, the smaller the boundary effect on the hydrodynamic pressures. As it may be observed from Figure 23, for a stiff and vertical dam (which is generally the case for concrete gravity dams), the results for $L / H<5$ differ significantly from the most accurate solution, whereas the rest are reasonably close. Similarly, it can be seen from Figure 26 that for a flexible and sloped dam (which is generally the case for earth dams), the results for $L / H<1$ differ from the most accurate solution. Consequently, it is suggested that for a stiff dam with a vertical face (such as concrete gravity dams), the upstream boundary should be placed at a distance of more than five times the height of the reservoir. On the other hand, for a flexible and sloped dam (such as earth dams), the upstream boundary should be placed at a distance equal to two to three times the height of the reservoir. 
It should be noted that the negative values of the normalised hydrodynamic pressure on the flexible dam in Figures 25 and 26 are a result of the deformation of the dam. They are smaller than the hydrostatic pressure and therefore the total (hydrostatic + hydrodynamic) reservoir pressure is positive (compressive). It should also be noted that for the case of the stiff dam (Figures 23 \& 24), the hydrodynamic pressures are smaller for the sloped dam than for the vertical dam which is in agreement with the results of Zangar [44]. However, for the flexible dam (Figures 25 \& 26) the hydrodynamic pressures on the sloped dam seem to be larger than on the vertical dam. This is believed to be due to the vibration of the dam body which gives rise to dam-reservoir interaction effects which may amplify the response of the dam. The latter issue has been addressed to a great extent by other researchers [7] [17] [18] and it is beyond the scope of this work.

\subsection{Shear stiffness of water}

Although the shear stresses in the water are considered negligible, a nominal value of shear modulus is usually employed in numerical analysis to avoid instability of the numerical solution. The critical question is what is the maximum value of shear modulus that can be assigned to water, $G_{w}$, without affecting the results significantly and without causing propagation of shear waves. In order to identify this value, further analyses were undertaken for different values of the shear modulus, which was expressed in terms of the bulk modulus of the water, $K_{w}$, as listed in Table 3 . A stiff dam with a vertical upstream face and $\mathrm{L} / \mathrm{H}=15$ was considered.

Figure 27 shows the distribution of the peak normalised hydrodynamic pressure on the upstream face of the dam. It is considered that the case with the smallest $G_{w}\left(=0.00005 \% K_{w}\right)$ is the most accurate because it does not allow propagation of shear waves. It is clear from Figure 27 that the results corresponding to a value of the shear modulus larger than $0.5 \% K_{w}$ deviate from the most accurate solution, whereas the results for $0.1 \%$ and below are quite close. It is therefore recommended that the value of the shear modulus assigned to reservoir water should be kept below $0.1 \%$ of the bulk modulus, $K_{w}$, i.e. less than $2000 \mathrm{kPa}$.

\section{Conclusions}

Several issues related to the numerical modelling of the hydrodynamic pressures on dams by discretising the reservoir domain with displacement- 
Table 3: Values of the Shear Modulus, $G_{w}$ assigned to the reservoir water elements

\begin{tabular}{|c|c|c|}
\hline CASE & Shear Modulus, $G_{w}[\mathrm{kPa}]$ & $\% K_{w}$ \\
\hline 1 & 220000 & 10 \\
2 & 110000 & 5 \\
3 & 22000 & 1 \\
4 & 11000 & 0.5 \\
5 & 2200 & 0.1 \\
6 & 1100 & 0.05 \\
7 & 220 & 0.01 \\
8 & 110 & 0.005 \\
9 & 22 & 0.001 \\
10 & 11 & 0.0005 \\
11 & 2.2 & 0.0001 \\
12 & 1.1 & 0.00005 \\
\hline
\end{tabular}

based isoparametric solid finite elements were explored. Both stiff and flexible dams with vertical and sloped upstream faces were investigated under ramp, harmonic and random acceleration loads. The results have been compared to analytical solutions where available and showed a good agreement. The same approach may be used in analyses of other waterfront structures such as quay walls. The conclusions of this study may be summarised as follows:

- As far as the truncated upstream boundary of the reservoir is concerned, the Viscous and Cone BCs can be employed to absorb the radiating waves. Their performance in a wide range of loading frequencies has been confirmed and it is almost identical. The Free and Viscous + hydrostatic pressures BCs were also examined and did not perform satisfactorily.

- At the interface between the reservoir and the dam and the reservoir and the foundation, interface elements should be used in order to allow relative movement between the water and the solid materials. Appropriate values should be used for the shear and normal stiffness of these elements.

- The reservoir water should not be treated as incompressible in order not to underestimate possible resonance for loading frequencies close 


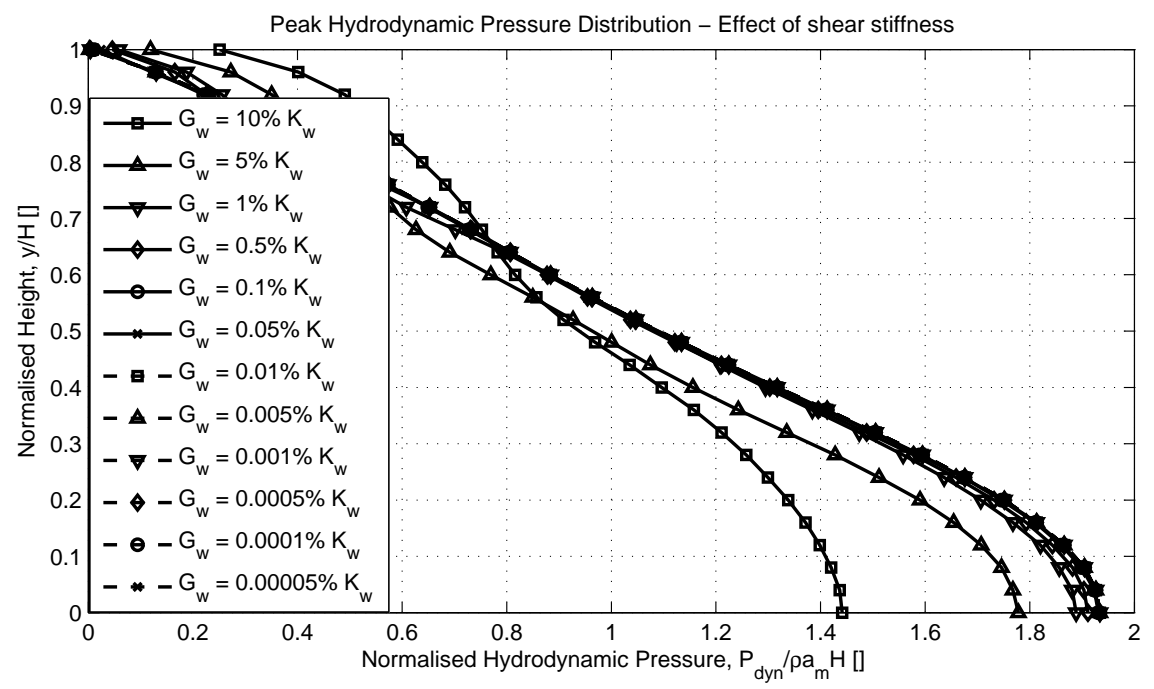

Figure 27: Distribution of the peak hydrodynamic pressure on a stiff dam for different values of the shear modulus of the water, $G_{w}$

to the fundamental frequencies of the reservoir and not to overestimate pressures for higher frequency loads.

- The size of the reservoir elements should be smaller than a fifth of the acoustic ( $p$-wave) wavelength of the water.

- For a stiff dam with a vertical upstream face (such as concrete gravity dams), the upstream reservoir boundary should be placed at a distance of five times the height of the reservoir from the upstream face of the dam. This distance may be reduced for a flexible dam with a sloped upstream face (such as earth dams) down to two to three times the height of the reservoir.

- The value of the shear stiffness assigned to water, $G_{w}$, should be smaller than $0.1 \%$ of the real value of the bulk modulus of the water, $K_{w}$.

\section{Acknowledgements}

The first author would like to express his acknowledgements to the Engineering and Physical Sciences Research Council (EPSRC), UK for the award of a Research Studentship. 


\section{References}

[1] Ambraseys, N. N., 1960, On the shear response of a two-dimensional truncated wedge subjected to arbitrary disturbance, Bull. Seism. Soc. Am., 50, 1, 45-56.

[2] Bathe, J. K., 1996, Finite element procedures in engineering analysis, Prentice Hall, New Jersey.

[3] Bouaanani, N., Paultre, P., Proulx, J., 2003, A closed-form formulation for earthquake-induced hudrodynamic pressure on gravity dams, J. Sound Vib., 261, 573-582.

[4] Chopra, A. K., 1966, Earthquake effects on dams, PhD Thesis, University of California, Berkeley.

[5] Chopra, A. K., 1967, Earthquake response of earth dams, J. Soil Mech. Found. Div., ASCE, 93, SM2, 1399-1412.

[6] Chopra, A. K., 1967, Hydrodynamic pressures on dams during earthquakes, J. Engrg. Mech. Div., ASCE, 93, EM6, 205-223.

[7] Chopra, A. K., 1968, Earthquake behavior of reservoir-dam systems, J. Engrg. Mech. Div., ASCE, 94, EM6, 1475-1500.

[8] Chung, J., Hulbert, G. M., 1993, A time integration algorithm for structural dynamics with improved numerical dissipation: the generalised- $\alpha$ method, J. Appl. Mech., 60, 371-375.

[9] Chwang, A. T., 1978, Hydrodynamic pressures on sloping dams during earthquakes. Part 2: Exact theory, J. Fluid Mech., 87, 2, 343-348.

[10] Dakoulas, P., Gazetas, G., 1985, A class of inhomogeneous shear models for seismic response of dams and embankments, Soil Dyn. and Earthq. Engrg., 4, 4, 166-182.

[11] Dakoulas, P., Gazetas, G., 1987, Vibration characteristics of dams in narrow canyons, J. Geotech. Engrg. Div., ASCE, 113, 8, 899-904.

[12] Day, R. A., Potts, D. M., 1994, Zero thickness interface elements - Numerical stability and application, Int. J. for Num. Anal. Meth. Geomech., $18,10,689-708$. 
[13] Elia, G., Amorosi, A., Chan, C., Kavvadas, M. J., 2010, Fully coupled dynamic analysis of an earth dam, Geotechnique, 61, 7, 549-563.

[14] Gazetas, G. 1987, Seismic response of earth dams: some recent developments, Soil Dyn. and Earthq. Engrg., 6, 1, 3-47.

[15] Gogoi, I., Maity, D., 2010, A novel procedure for determination of hydrodynamic pressure along upstream face of dams due to earthquakes, Comput. Struct., 88, 539-548.

[16] Hall, J. F., Chopra, A. K., 1982, Two-dimensional dynamic analysis of concrete gravity and embankment dams including hydrodynamic effects, Earthq. Engrg. and Struct. Dyn., 10, 2, 305-332.

[17] Hall, J. F., Chopra, A. K., 1982, Hydrodynamic effects in earthquake response of embankment dams, J. Geotech. Engrg. Div., ASCE, 108, GT4, 591-597.

[18] Hall, J. F., Chopra, A. K., 1982, Hydrodynamic effects in the dynamic response of concrete gravity dams, Earthq. Engrg. and Struct. Dyn., 10, 2, 333-345.

[19] Higdon, R. L., 1987, Numerical absorbing boundary conditions for the wave equation, Math. Comp., 176, 65-90.

[20] Kellezi, L. X., 2000, Local transmitting boundaries for transient elastic analysis, Soil Dyn. and Earthq. Engrg., 19, 7, 533-547.

[21] Kontoe, S., Zdravković, L., Potts. D.M., 2008, An assessment of time integration schemes for dynamic geotechnical problems, Comput. and Geotech., 2008, 35, 253-264.

[22] Kontoe, S., Zdravković, L., Potts. D. M., 2009, An assessment of the domain reduction method as an advanced boundary condition and some pitfalls in the use of conventional absorbing boundaries, Int. J. for Num. Anal. Meth. Geomech., 33, 309-330.

[23] Küçükarslan, S., Coşkun, S. B., Taşkin, B., 2005, Transient analysis of dam-reservoir interaction including the reservoir bottom effects, J. Fluids and Struct., 20, 1073-1084. 
[24] Kuhlemeyer, R. L., Lysmer, J., 1973, Finite element method accuracy for wave propagation problems, J. Soil Mech. and Found. Div., ASCE, 99, 5, 421-427.

[25] Liu, P. L. F., 1986, Hydrodynamic pressures on rigid dams during earthquakes, J. Fluid Mech., 165, 131-145.

[26] Lysmer, J., Kuhlemeyer, R. L., 1969, Finite dynamic model for infinite media, J. Engrg. Mech. Div., ASCE, 95, 4, 859-877.

[27] Miquel, B., Bouaanani, N., 2010, Simplified evaluation of the vibration period and seismic response of gravity dam-water systems, Eng. Struct., $32,2488-2502$.

[28] Parrinello, F., Borino, G., 2007, Lagrangian finite element modelling of dam-fluid interaction: Accurate absorbing boundary conditions, Comput. and Struct., 85, 932-943.

[29] Potts, D. M., Zdravković, L., 1999, Finite element analysis in geotechnical engineering: Theory, Thomas Telford, London.

[30] Saini, S. S., Bettess, P., Zienkiewicz, O. C., 1978, Coupled hydrodynamic response of concrete gravity dams using finite and infinite elements, Earthq. Engrg. and Struct. Dyn., 6, 4, 363-374.

[31] Samii, A., Lotfi, V., 2012, High-order adjustable boundary condition for absorbing evanescent modes of waveguides and its application in coupled fluid-structure analysis, Wave motion, 49, 238-257.

[32] Sarma, S. K., 1979, Stability analysis of embankments and slopes, J. Geotech. Engrg. Div., ASCE, 105, 12, 1511 - 1524.

[33] Seghir, A., Tahakourt, A., Bonnet, G., 2009, Coupling FEM and symmetric BEM for dynamic interaction of dam-reservoir systems, Eng. Anal. Bound. Elem., 33, 1201-1210.

[34] Sommerfeld, A. J. W., 1912, Die greensche funktion der schwingungsgleichung, Jahresbericht der Deutschen Methematiker-Vereinigung, 21, 309-353.

[35] Sommerfeld, A. J. W., 1949, Partial Differential Equations in Physics, Academic Press, New York. 
[36] Terzaghi, K., 1950, Mechanics of landslides, Technical Report Engineering, Geology Volume, The Geological Survey of America.

[37] Tsai, C. S., Lee, G. C., Ketter, R. L., 1990, A semi-analytical method for time-domain analyses of dam-reservoir interactions, Int. J. for Num. Meth. Engrg., 29, 913-933.

[38] Von Estorff O., Antes H., 1991, On FEM-BEM coupling for fluidstructure interaction analyses in the time domain, Int. J. for Num. Meth. Engrg., 31, 6, 1151-1168.

[39] Wang, X., Jin, F., Prempramote, S., Song, C., 2011, Time-domain analysis of gravity dam-reservoir interaction using high-order doubly asymptotic open boundary, Comput. Struct., 89, 668-680.

[40] Westergaard, H. M., 1933, Water pressures on dams during earthquakes, Transactions, ASCE, 98, 1, 418-433.

[41] Wilson, E. L., Khalvati, M., 1983, Finite elements for the dynamic analysis of fluid-solid systems, Int. J. for Num. Meth. Engrg., 19, 11, 16571668.

[42] Woodward, P. K., Griffiths, D. V., 1996, Influence of viscous damping on the dynamic analysis of an earth dam using simple constitutive models, Comput. and Geotech., 19, 3, 245-263.

[43] Zangar, C. N., Haefeli, R. J., 1952, Electric analog indicates effect of horizontal earthquake shock on dams, Civil Engrg., 22, 4, 278-279.

[44] Zangar, C. N., 1953, Hydrodynamic pressures on dams due to horizontal earthquakes, Proc. Soc. Exp. Stress Anal., 10, 93-102.

\section{Appendix A. Nomenclature}

a maximum value of ramp acceleration load $\left(=1 \mathrm{~m} / \mathrm{s}^{2}\right)$

$a_{o} \quad$ amplitude of harmonic acceleration load $\left(=1 \mathrm{~m} / \mathrm{s}^{2}\right)$

$a_{m} \quad$ maximum value of random acceleration load $(=0.04 \mathrm{~g})$

$a(t)$ acceleration load time history

$B$ breadth of dam slope face

d maximum element size 
$f \quad$ frequency of harmonic load

$f_{1} \quad$ fundamental frequency of the reservoir

$F_{d y n}$ total hydrodynamic force on the upstream reservoir face

$F_{s t} \quad$ total hydrostatic force on the upstream reservoir face

$g \quad$ acceleration of gravity $\left(=9.81 \mathrm{~m} / \mathrm{s}^{2}\right)$

$G_{w} \quad$ shear modulus of water

$H$ height of the dam

$K_{d} \quad$ bulk modulus of the dam materials

$k_{N} \quad$ normal stiffness of interface elements

$k_{S} \quad$ shear stiffness of interface elements

$K_{w} \quad$ bulk modulus of water $\left(=2.2 \cdot 10^{6} \mathrm{kPa}\right)$

$L \quad$ length of the reservoir

$P_{d y n}$ hydrodynamic pressure at the base of the dam

$r \quad$ distance of the upstream reservoir boundary from the excitation source

$t$ time

$T$ thickness of the dam foundation

$\dot{u} \quad$ velocity of water in the horizontal direction

$\ddot{u}_{g} \quad$ horizontal ground acceleration

$V_{p} \quad$ p-wave velocity of water $(=1483 \mathrm{~m} / \mathrm{s})$

$V_{s} \quad$ shear wave velocity of the dam materials

$W \quad$ width of the dam crest

$y \quad$ vertical distance from the base of the dam

$\gamma_{w} \quad$ unit weight of water $\left(=9.81 \mathrm{kN} / \mathrm{m}^{3}\right)$

$\lambda \quad$ wavelength

$\lambda_{n} \quad \mathrm{n}^{\text {th }}$ wavelength

$\rho \quad$ mass density of water $\left(=1000 \mathrm{~kg} / \mathrm{m}^{3}\right)$

$\sigma \quad$ normal stress on the upstream reservoir boundary

$\omega \quad$ circular frequency of harmonic load

$\omega_{1} \quad$ fundamental circular freqency of the reservoir

$\Omega \quad$ frequency ratio $\left(=\omega / \omega_{1}\right)$ 